Disponível em

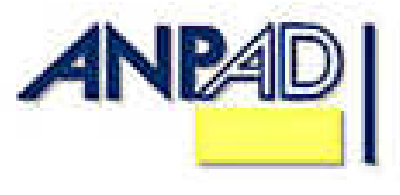

RAC, Curitiba, v. 15, n. 6, art. 2,

pp. 993-1015, Nov./Dez. 2011

http://www.anpad.org.br/rac

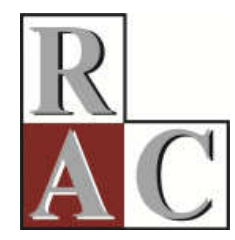

\title{
Trabalhadores Afastados por Transtornos Mentais e de Comportamento: o Retorno ao Ambiente de Trabalho e suas Consequências na Vida Laboral e Pessoal de Alguns Bancários
}

Workers Removed for Mental and Behavioral Disorders: the Return to the Workplace
and Its Impact on the Personal and Working Life of some Bank Employees

Marilene Olivier * E-mail: marilene.olivier@gmail.com Universidade Federal do Espírito Santo - UFES

Vitória, ES, Brasil.

Cristiani Storch Perez

E-mail: cristiani.perez@ seger.es.gov.br Secretaria de Gestão de Recursos Humanos do Espírito Santo - SEGER Vitória, ES, Brasil.

Simone da Costa Fernandes Behr E-mail: fernandessimone26@gmail.com Universidade Federal do Espírito Santo - UFES Vitória, ES, Brasil.

* Endereço: Marilene Olivier

UFES, Av. Fernando Ferrari, 514, Goiabeiras, Vitória/ES, 29075-910.

Copyright (C) 2011 RAC. Todos os direitos, até mesmo de tradução, são reservados. É permitido citar parte de artigos sem autorização prévia, desde que seja identificada a fonte. 


\title{
Resumo
}

A pesquisa foi realizada em um Banco Estatal localizado em um Estado da região sudeste que, a partir da adoção de tecnologias, instituiu mudanças em cargos e funções, exigindo de seus funcionários a consecução de objetivos e metas derivados das pressões do mercado. A partir das mudanças implementadas, começaram a surgir casos de trabalhadores com quadros de depressão e estresse que necessitaram afastar-se de suas atividades. O objetivo da pesquisa realizada foi fazer um estudo de como passou a ser o cotidiano dos trabalhadores do Banco, após gozarem licença médica, devido a transtornos mentais e comportamentais, tanto no seu aspecto laboral quanto pessoal. A discussão teórica inicia-se com as transformações do mercado de trabalho, passando para os transtornos mentais e de comportamento decorrentes do novo contexto organizacional. Foram referenciados autores que trataram dos dois tipos de transtorno mais observados no estudo, ou seja, estresse e depressão e também a Teoria da Avaliação Cognitiva e a Teoria da Justiça Organizacional. Foi utilizada uma abordagem qualitativa, valendo-se da técnica de análise de conteúdo para o tratamento dos dados, que foram coletados por meio do autorrelato dos funcionários acometidos pelos transtornos. Os resultados apontam a continuidade da presença de estressores no ambiente de trabalho, as dificuldades das relações interpessoais e a falta de um programa de reintegração dos trabalhadores no ambiente de trabalho.

Palavras-chave: retorno ao trabalho; depressão; estresse; transtornos mentais; transtornos de comportamento.

\begin{abstract}
The survey was conducted in a State Bank located in a southeastern state that adopted technologies that led to changes in positions and functions, which required employees to achieve goals and objectives derived from market pressures. The implemented changes began to produce cases of depression and stress amongst workers, who had to be removed from their activities. The survey's goal was to study how the everyday life of the bank's employees had changed following medical leave due to mental and behavioral disorders, evaluating both personal and professional aspects. The theoretical discussion begins with the transformation of the labor market and goes on to analyze mental and behavioral disorders resulting from the new organizational context. References are made to authors who dealt with both of the disorders that are most referred to in the study, i.e., stress and depression, in addition to the Theory of Cognitive Evaluation the Theory of Organizational Justice. We used a qualitative approach, through the technique of content analysis for the treatment of the data that were collected through the self-reporting of employees affected by the disorders. The results show the continued presence of stressors in the workplace, the difficulties of interpersonal relationships and lack of a reintegration program for workers in the workplace.
\end{abstract}

Key words: return to work; depression; stress; mental disorders; behavior disorders. 


\section{Introdução}

Por decorrência dos avanços tecnológicos, mudanças significativas surgiram nas empresas que, ao responderem aos apelos da competitividade, passaram a exigir muito mais do ser humano, que se viu compelido a buscar constantemente novas habilidades e competências para se manter no seu posto de trabalho. Os caixas de banco tiveram o número de postos de trabalho reduzido, devido à implementação de sistemas de auto-atendimento em caixas automatizados, fazendo com que os trabalhadores tivessem que assumir novas atribuições diferentes daquelas para as quais foram contratados inicialmente, com metas difíceis de serem atingidas, consideradas por alguns bancários de natureza coercitiva (Grisci \& Bessi, 2004).

Como resultados do processo anteriormente descrito, para a instituição, no caso um banco, geram-se benefícios a curto prazo tais como: o aumento da captação, aumento do lucro contábil, aumento do número de clientes, entre outros. Por outro lado, o número de casos de afastamentos por estresse e depressão aumentou significativamente, conforme já constatado por Alexanderson e Norlund (2004) e Vaez, Rylander, Nygren, Asberg e Alexanderson (2007), para os quais os transtornos mentais já são a segunda causa mais frequente de ausência do trabalho por motivo de doença, depois dos distúrbios osteomusculares.

Como pode ser visto em Murta e Tróccoli (2004, p. 39), "as doenças ocupacionais têm tido alta incidência e levado à diminuição de produtividade, ao aumento de indenizações e demandas judiciais contra os empregadores". Os transtornos mentais e de comportamento são decorrentes das dificuldades de enfrentamento ou elaboração dos problemas vivenciados pelo ser humano. De acordo com Laplanche e Pontalis (2004), a expressão enfrentamento é utilizada para designar o esforço que a pessoa faz para vencer as dificuldades que percebe em relação ao meio no qual se insere. Quando o resultado do esforço despendido é em vão, de modo geral, há uma acumulação de excitações mentais que podem ter como consequência o aparecimento de sintomas de transtornos mentais.

Com uma alta demanda de trabalho por enfrentar, o empregado vem sentindo-se ameaçado e pressionado por meio de diversos quadros, tais como os seguintes: maior insegurança no emprego, dificuldade nas relações interpessoais, assédio moral, problemas emocionais, moral baixo, diminuição da motivação e da lealdade, todos considerados fatores estressores do ambiente de trabalho. Como se não bastasse, os trabalhadores apresentam ao mesmo tempo um repertório de enfrentamento deficitário, dando origem ao estresse ocupacional e à depressão, entre outros (Cooper, 2007).

O Banco pesquisado é uma sociedade de economia mista e capital aberto, cujas ações pertencem, em sua maioria, ao Estado. A organização possui 2.356 empregados em seu quadro funcional e a maior parte de seus clientes constitui-se em servidores públicos estaduais e municipais de um Estado da região sudeste. Atua com prioridade na oferta de linhas de financiamento voltadas para a inclusão social, destacando-se o microcrédito e o crédito rural. Este Banco tem sido caracterizado por ser uma instituição financeira com alto índice de reclamações trabalhistas e elevado número de registro de acidentes de trabalho e doenças relacionadas ao trabalho.

No caso do Banco em questão, percebeu-se a evidência da presença de elementos de retaliação, relação desarmoniosa entre os que passaram e os que não passaram por um afastamento decorrente de transtorno mental e/ou comportamental e a presença de estressores ocupacionais originados das pressões do ambiente organizacional. A percepção se deu devido às queixas iniciais apresentadas por alguns trabalhadores do Banco, em encontros informais com as pesquisadoras. $\mathrm{O}$ sofrimento manifestado e os relatos espontâneos sugeriram, inicialmente, uma situação de trabalho que parecia ir além do estresse. O ponto central verbalizado pelos bancários queixosos foi a dificuldade de enfrentamento de problemas vivenciados no desempenho de suas tarefas e em suas relações de trabalho decorrentes das mudanças ocorridas no ambiente de instituições bancárias.

Em termos de referência ao assunto, Liu e Perrewé (2005) buscaram integrar uma perspectiva emocional na explicação de reações individuais à mudança, destacando experiências emocionais de 
empregados durante o processo sem, no entanto, fazerem registro da continuidade ou não dos elementos emocionais após o afastamento do empregado e seu retorno ao ambiente de trabalho. Com o levantamento bibliográfico realizado, verificou-se a escassez de publicações a respeito do assunto, tendo sido encontrado apenas o trabalho de Koopmans et al. (2011), cujo resultado mostrou que após um episódio relacionado a transtornos mentais comuns, é maior o risco de absenteísmo recorrente, devido a doenças como estresse e depressão. As evidências obtidas, a partir de queixas apresentadas por trabalhadores do Banco pesquisado, conduziram ao seguinte questionamento: Qual a percepção de alguns trabalhadores do Banco, ao retornarem ao trabalho após um período de licença médica, devido a transtornos mentais e de comportamento, em relação à sua vida laboral e pessoal?

O questionamento surgiu do fato de que o trabalho pode ser visto tanto como uma das fontes de satisfação de necessidades humanas (auto-realização, relações interpessoais e sobrevivência), quanto uma fonte de adoecimento, pois no desempenho das atividades laborais, de modo geral, o trabalhador se defronta com riscos à sua saúde, quer seja física ou mental. Em alguns casos, como nos enfrentamentos ligados aos processos mentais, nem sempre o colaborador tem condições de se proteger dos riscos.

A partir das considerações feitas anteriormente, julgou-se importante fazer um estudo de como passou a ser o cotidiano dos trabalhadores deste Banco Público Estadual, após gozarem licença médica, devido a transtornos mentais e comportamentais, tanto no seu aspecto laboral quanto pessoal. Compreender a realidade mencionada mostra-se relevante para os bancários, uma vez que, conforme Koopmans et al. (2011), embora a taxa de recorrência dos distúrbios mentais seja alta, os afastamentos devido aos transtornos mentais comuns, ainda não foram estudados. Os autores definiram os transtornos mentais comuns usando como parâmetro a classificação da Organização Mundial da Saúde (OMS), particularmente o Código Internacional de Doenças 10 (CID - 10). O código contém a descrição das características dos seguintes transtornos, entre outros: Sintomas de Socorro (CID-10 R45), Transtornos Relacionados ao Estresse (CID 10 - F43), incluindo reações de estresse agudo e desordens de ajustamento), Transtornos Depressivos (CID-10 F32), Transtornos de Ansiedade (CID10 F40 e F41) e outros transtornos psiquiátricos, tais como Psicoses, Transtorno Bipolar e distúrbios causados por substâncias psicoativas (OMS, 1993).

Segundo Liu e Perrewé (2005), transtornos comportamentais ocorrem porque grandes mudanças intencionais provocam consequências de natureza emocional para os trabalhadores, podendo ser a causa de doenças psicossomáticas.

Pretendeu-se, portanto, identificar e descrever, na percepção de alguns trabalhadores de um Banco Público Estadual, quais as consequências em sua vida laboral e pessoal, ao retornarem ao trabalho, após um período de licença médica, devido a transtornos mentais e de comportamento.

A seguir serão descritos os procedimentos metodológicos adotados.

\section{Aspectos Metodológicos}

Esta pesquisa é de natureza qualitativa (Moreira, 2004), na medida em que se buscou descrever os modos pelos quais os trabalhadores do Banco perceberam o significado do que estavam vivenciando, após retornarem da licença médica, em termos das condições em que estavam desempenhando suas atividades laborais e, também, desenvolvendo suas relações interpessoais no cotidiano do banco e com seus familiares.

Num primeiro momento, foi realizado um levantamento junto aos gestores de Recursos Humanos do Banco, a fim de verificar as estatísticas dos casos de funcionários afastados por transtornos mentais e de comportamento, mas os registros administrativos não apresentaram informações que pudessem ser utilizadas na pesquisa, pois se tratava apenas do período de duração da 
licença médica. Teve-se, assim, acesso ao nome de todos os afastados em 2006, 2007 e 2008 , sem distinção do quadro clínico e da lotação do profissional.

Em conversas informais com os responsáveis pelo setor de Recursos Humanos, buscou-se a indicação de cinco empregados que poderiam colaborar com a pesquisa. Os sujeitos deveriam ter passado por um período de afastamento devido a algum tipo de transtorno emocional ou comportamental e terem retornado ao trabalho.

A partir dos cinco primeiros entrevistados obteve-se o nome e a indicação de outros que fizeram parte da pesquisa. Foi um processo de difícil convencimento, mas no final foram realizadas vinte e duas entrevistas. As resistências dos profissionais foram sendo quebradas na medida em que entendiam os objetivos da pesquisa como oportunidade para manifestar seu olhar a respeito da própria situação vivida.

O primeiro contato com os funcionários foi feito por e-mail, momento no qual se buscou coletar as primeiras impressões, a fim de identificar algumas questões básicas que dessem subsídio para a elaboração da pauta da entrevista. Posteriormente foram coletados outros dados via telefone e, por fim, foram realizadas as entrevistas.

Optou-se então pelo autorrelato em livre narrativa com dois focos principais: como era o trabalho e a vida pessoal do entrevistado antes da constatação do transtorno e após o retorno ao trabalho. De acordo com Ganster (2008), há suporte para o autorrelato, tanto do ponto de vista teórico quanto pragmático, sendo que no caso do auto-relato em livre narrativa não se deve seguir um roteiro de questões muito delimitado. Existe um roteiro pré-elaborado que serve como um check list; as perguntas só são feitas quando a livre narrativa não contempla o aspecto listado.

A primeira parte da entrevista foi dirigida aos dados sociodemográficos, quais sejam: gênero, estado civil, número de filhos e respectiva idade, idade do entrevistado e tempo de serviço no Banco. A segunda parte teve como suporte o check list, com perguntas que abordavam o impacto da doença sobre o sujeito; a realização do tratamento; tempo de licença médica; busca de ajuda junto a profissionais; discussão do problema de saúde junto aos profissionais procurados; descrição do trabalho, antes e depois, de pedir licença para tratamento; causas da necessidade de pedir licença médica; relação com a chefia e com os colegas, antes e depois da licença; hábitos cotidianos; alimentos consumidos; atividade física e hobbies praticados; consumo de cigarros e de bebidas, antes e depois da licença; ocorrência de mudança de peso; relacionamento social e familiar, entre outras.

As entrevistas gravadas foram transcritas na íntegra e posteriormente passaram pela Análise de Conteúdo. Tentou-se ir além das evidências, fazer mais do que uma leitura cuidadosa do material em estudo. Inicialmente foram grifadas todas as partes do texto consideradas relevantes. Logo em seguida, os trechos foram transcritos para blocos de assuntos correlatos, que deram origem às categorias, quais sejam: elementos sociodemográficos; estilo de vida; ambiente de trabalho; o afastamento do trabalho; as relações familiares e sociais; consequências no comportamento pessoal e relacionamentos interpessoais após o afastamento.

No próximo item serão abordados aspectos relacionados aos transtornos mentais, às doenças psicossomáticas, às relações interpessoais e ao ambiente de trabalho, explicitando-se os conceitos de transtorno, estresse e depressão por terem sido as principais causas de afastamento dos bancários que participaram da pesquisa.

\section{Alguns Conceitos Referentes aos Transtornos Mentais e Comportamentais}

De acordo com a Organização Mundial da Saúde, OMS (1993) que publica o CID-10, é recomendada a utilização do termo transtorno em substituição a expressões como doença ou enfermidade, que causam polêmica. Trata-se do CID-10 de um documento técnico da área que 
padroniza a nomenclatura utilizada pelos profissionais da área de saúde. Assim, transtorno é utilizado para "indicar a existência de um conjunto de sintomas ou comportamentos clinicamente reconhecíveis, associados, na maioria dos casos, a sofrimento e interferência com funções pessoais" (OMS, 1993, p. 5). Existem diversos tipos de transtornos, destacando-se para este estudo os transtornos do humor (afetivos), que incluem as manias, a bipolaridade, depressão e outros; transtornos neuróticos, relacionados ao estresse e somatoformes, onde estão as fobias, o pânico, a obsessão, a compulsão e o estresse grave; síndromes comportamentais associadas a perturbações fisiológicas e fatores físicos, onde são encontrados os transtornos alimentares, os transtornos do sono, disfunções sexuais e abusos de substâncias que não produzem dependência (OMS, 1993).

Na opinião de Zampier e Stefano (2004, p. 13), "a forma de organização das sociedades contemporâneas tem constituído um solo fértil para o desenvolvimento de doenças psicossomáticas e biológicas". A pressão contra a grande massa de trabalhadores é constante, e em termos psicológicos o sofrimento é imenso, pois as forças de mercado fazem com que milhares de pessoas se sintam tensas e ansiosas, se têm como única maneira de sobrevivência; há ainda a própria força de trabalho, que pode ser dispensada a qualquer momento (Olivier \& Behr, 2006). O medo de perder o emprego faz com que o funcionário desenvolva um nível de conflito interno que, muitas vezes, chega a um ponto crítico, trazendo não só problemas de saúde como também familiares (Halbesleben \& Zelllars, 2007).

De acordo com Vicente (2005, p. 259), "existe uma relação entre as doenças psicossomáticas, os conflitos psíquicos e as modificações fisiológicas". O recalcamento operado na mente do sujeito, por impossibilidade de expressão de emoções geradoras de um conflito psíquico, provoca estados diferenciados de tensão fisiológica. Quando se reprimem, agressividade, medo e culpabilidade provocam disfunções em órgãos, por impulsos de tensões emocionais acumuladas. Pode, então, haver uma reação complexa de componentes físicos e psicológicos resultantes da exposição do sujeito: este não possui recursos suficientes para o enfrentamento da situação vivida. Se as causas se prolongam, o trabalhador pode ter afetados os aspectos da psique e do corpo (Lipp, 1996), como também desenvolver um quadro de burnout, que tem sido associado à depressão e à disfunção mental, por precipitar efeitos negativos em termos de saúde mental, configurados pela depressão, ansiedade e diminuição da autoestima (Chamon, Marinho, \& Oliveira, 2006).

Em sentido semelhante, Oliveira, Kilimnik e Silva (2005) afirmam que a manifestação patológica do estresse no ambiente de trabalho depende de como o indivíduo - enquanto um ser biológico, subjetivo, social e cultural - interage com o ambiente. Isso significa dizer que, dependendo da forma como o trabalho está organizado e de como é executado pelo trabalhador, podem ser gerados efeitos negativos, entre os quais estão situações que levam ao adoecimento e à morte. E é Dalgalarrondo (2008) quem apresenta diversos estados de concentração detectados no ambiente de trabalho, considerados sintomas de transtornos mentais e de comportamento quais sejam: a hipoprosexia, a aprosexia, a hiperprosexia, a distração e a distrabilidade.

A hipoprosexia consiste na perda básica da capacidade de concentração, com o aumento da fadiga, da dificuldade de perceber os estímulos ambientais e para lembrar as coisas, bem como em pensar, raciocinar e integrar informações. Denomina-se aprosexia a total perda da capacidade de atenção. A hiperprosexia, por sua vez, consiste em um estado de atenção exagerado, no qual o sujeito se exaure por prestar atenção a detalhes que são dispensáveis na convivência diária com as demais pessoas. A distração configura-se como um sinal de que a pessoa está se concentrando em demasia em determinado conteúdo ou objeto. E, por fim, a distrabilidade, que é um estado patológico onde há dificuldade do sujeito deter-se em algo que implique um esforço produtivo. Os conceitos descritos foram extraídos de Dalgalarrondo (2008), por serem importantes na compreensão dos transtornos, com destaque para o estresse e a depressão.

Quando o trabalhador vivencia uma situação desgastante, pode apresentar reações associadas a diversos mecanismos patogênicos, cognitivos, afetivos, de conduta ou fisiológicos, destacando-se o estresse (Murta \& Tróccoli, 2004). De acordo com Zampier e Stefano (2004), o estresse pode ser conceituado como estado emocional desagradável, decorrente da insegurança das pessoas quanto à própria capacidade para enfrentar um desafio em relação a algo que lhes é valioso. 
Para Rossi (2007) entre as principais causas do estresse estão as seguintes: incerteza, sobrecarga de trabalho, relações interpessoais, tecnologia, desempenho da tarefa, problemas emocionais, assédio moral, rituais e procedimentos desnecessários, entre outros. Às diversas causas do estresse somam-se os fatores, que Ballone (2002) já havia detectado em relação ao estresse ocupacional, que são: o aumento do volume de trabalho; os conflitos diários no trabalho; as pressões sofridas pelo trabalhador; a falta de compreensão e tolerância da chefia, que também se vê pressionada; todo um ambiente desfavorável ao sujeito e o exercício de funções que são sentidas como inadequadas. Os fatores relacionados ao estresse ocupacional podem resultar em: afastamento do trabalho; intervenção hospitalar; desequilíbrio familiar; perda do emprego e constrangimento no trabalho e na sociedade. Tais elementos ou situações podem gerar consequências também para a organização, podendo ocorrer: perda de oportunidades no mercado; queda de produtividade; intensificação do absenteísmo e prejuízos financeiros (Paiva \& Couto, 2007).

Quando o trabalhador está em um estado emocional positivo vale-se de estratégias de enfrentamento saudáveis, como tranquilidade, esperança e bem-estar, que são sentimentos que atuam no sentido de um bom funcionamento do próprio organismo, favorecendo comportamentos de saúde e potenciando relações interpessoais gratificantes (Chamon et al., 2006). Porém, de acordo com Ayres, Brito e Torquato (2002), existe também o enfrentamento deficitário, que se dá quando o trabalhador faz uso de estratégias inapropriadas para o contexto, como, por exemplo, tentar desvencilhar-se rapidamente das suas tarefas, ancorar-se em vícios e isolar-se dos demais, comportamento que pode facilitar a presença de fontes de estresse que produzem alterações fisiológicas, tais como a queda da imunidade e aumento ou queda da pressão arterial, tornando o trabalhador mais vulnerável a outros quadros somáticos.

Por outro lado, Nakayama (1997) trata de um tipo específico de estresse, que se manifesta quando o trabalhador percebe o desequilíbrio entre as demandas existentes no trabalho e sua habilidade ou possibilidade para responder a elas. Trata-se então da discrepância entre a percepção do nível de demanda e a condição percebida pelo sujeito para enfrentá-las. A discrepância percebida, de modo geral, leva a uma associação com as emoções negativas, incluindo a sensação de mal-estar e desconforto, que surgem em quem vivencia o processo. Assim, o estresse ocupacional pode ser considerado como um conjunto de perturbações psicológicas ou sofrimento psíquico, associado às experiências de trabalho.

Tolfo, Philippi, Grandi, Piccinin e Noernberg (2005) trataram dos fatores de estresse decorrentes do processo de reestruturação produtiva, o que foi corroborado por Foster et al. (2007), quando estudaram a implantação do SAP R/3. Ambos os trabalhos estão em consonância com a pesquisa de tecnoestresse em bancários, de Ayres et al. (2002), focando as fontes, os sintomas e as estratégias defensivas. Tanure, Carvalho e Andrade (2007) também estudaram o estresse em nível corporativo, por meio da percepção dos que chegaram aos altos escalões organizacionais, abordando o uso do tempo, as mudanças, a sensação de dívida permanente, o orgulho pelo que faziam: enfim, o teatro corporativo. Os resultados mostram um desbalanceamento entre o tempo dedicado à carreira $\mathrm{e}$ às relações afetivas, familiares e ao lazer.

Com relação à depressão, de acordo com OMS (1993, p. 117), o episódio depressivo típico pode ser classificado em leve, moderado e grave, "nos quais o indivíduo sofre de humor deprimido, perda de interesse e prazer e energia reduzida, levando a uma fatigabilidade aumentada e atividade diminuída". Entre os sintomas também estão o cansaço marcante, a concentração e atenção reduzidas, ideias de culpa e inutilidade, visões desoladas e pessimistas do futuro, ideias ou atos autolesivos ou suicídio, angústia, sono perturbado e apetite diminuído. É importante registrar que os episódios depressivos podem vir acompanhados de sintomas somáticos, com quadros psicóticos ou sem eles.

Em uma dimensão mais abrangente, para Martin, Quirino e Mari (2007, p. 592), "a depressão é um grave problema de saúde pública, evidenciado pela importância das doenças mentais em relação às outras doenças. O transtorno compromete o cotidiano das pessoas no relacionamento social, seja na família, trabalho ou comunidade". A depressão consiste em um grande problema social, devido aos custos pessoais, ao prejuízo à saúde como um todo e à qualidade de vida. Constitui-se também em 
problema para as empresas, porque gera custos causados pela perda de produtividade, maior número de faltas ao trabalho, maior número de afastamentos e pelo prejuízo ao profissional.

Os conceitos de estresse e depressão foram explicitados, por terem sido os mais referenciados nos casos de afastamento dos bancários que participaram da pesquisa.

\section{Algumas Reflexões Teóricas Relacionadas aos Transtornos Mentais e de Comportamento}

Muitos têm sido os trabalhos publicados a respeito do estresse e depressão; mas poucos têm tratado do tema sob o enfoque específico dos transtornos mentais e de comportamento. A revisão de literatura realizada indicou três abordagens em relação ao tema: uso de estudos empíricos, ensaios e uso de modelos teóricos para a compreensão do assunto. As Tabelas 1, 2 e 3, respectivamente, apresentam esses estudos.

Tabela 1

Autores que Abordaram Transtornos Mentais e de Comportamento, a partir de Pesquisa Empírica

\begin{tabular}{|c|c|c|}
\hline Autor(es) & Teorias e Foco abordado & Contribuições \\
\hline \multirow[t]{2}{*}{ Koopmans et al. (2011) } & $\begin{array}{l}\text { Foram calculadas e analisadas as } \\
\text { correlações entre variáveis } \\
\text { dependentes e independentes: } \\
\text { diagnóstico inicial, idade, jornada de } \\
\text { trabalho, dados sociodemográficos, } \\
\text { entre outros. }\end{array}$ & $\begin{array}{l}\text { Os resultados mostram que os } \\
\text { trabalhadores que retornaram ao trabalho } \\
\text { após episódios de transtornos mentais } \\
\text { comuns têm maior risco de absenteísmo } \\
\text { recorrente, devido ao transtorno. }\end{array}$ \\
\hline & $\begin{array}{l}\text { O absenteísmo recorrente devido aos } \\
\text { transtornos mentais comuns. }\end{array}$ & \\
\hline \multirow[t]{2}{*}{ Nielsen et al. (2010) } & $\begin{array}{l}\text { Foi realizada uma análise de } \\
\text { regressão proporcional entre } \\
\text { variáveis como: problemas de saúde } \\
\text { mental, retorno ao trabalho, idade, } \\
\text { sexo, ocupação, razões autorrelatadas } \\
\text { de ausência, entre outros. }\end{array}$ & $\begin{array}{l}\text { Resultados relacionados às características } \\
\text { sociodemográficas podem ser úteis na } \\
\text { análise de concessão de auxílio-doença e } \\
\text { de reabilitação de profissionais vítimas do } \\
\text { transtorno. }\end{array}$ \\
\hline & $\begin{array}{l}\text { Preditores de retorno ao trabalho nos } \\
\text { casos em que o trabalhador apresenta } \\
\text { problemas de saúde mental: estresse, } \\
\text { ansiedade e depressão. }\end{array}$ & \\
\hline \multirow[t]{2}{*}{$\begin{array}{l}\text { Pluta e Accordino } \\
(2006)\end{array}$} & $\begin{array}{l}\text { Foi realizada uma análise hierárquica } \\
\text { de regressão entre o tempo de retorno } \\
\text { ao trabalho, no caso de trabalhadores } \\
\text { afastados por doenças psiquiátricas e } \\
\text { variáveis sociodemográficas. Foram } \\
\text { identificados alguns preditores de } \\
\text { retorno ao trabalho. }\end{array}$ & $\begin{array}{l}\text { Os investigadores mostram que as pessoas } \\
\text { que retornam ao trabalho após licença } \\
\text { psiquiátrica não têm, necessariamente, que } \\
\text { assumir atividades de menor importância } \\
\text { no ambiente organizacional. }\end{array}$ \\
\hline & $\begin{array}{l}\text { Estudo de preditores de retorno ao } \\
\text { trabalho para pessoas com } \\
\text { deficiências psiquiátricas. }\end{array}$ & \\
\hline
\end{tabular}

Nota. Fonte: Elaborado pelas autoras. 
Tabela 2

Autores que Abordaram Transtornos Mentais e de Comportamento Utilizando Teorias

\begin{tabular}{|c|c|c|}
\hline Autor(es) & Teorias e Foco abordado & Contribuições \\
\hline $\begin{array}{l}\text { D'Cruz e Noronha } \\
\text { (2010) }\end{array}$ & $\begin{array}{l}\text { - Teoria do Assédio Moral } \\
\text { - Teoria da Justiça Organizacional } \\
\text { O desejo e esforço das pessoas para se } \\
\text { tornarem profissionais e o regime opressivo } \\
\text { de trabalho. Sua pesquisa teve por objetivo } \\
\text { compreender as experiências daqueles que se } \\
\text { sentiram intimidados em suas relações } \\
\text { interpessoais no ambiente de trabalho. }\end{array}$ & $\begin{array}{l}\text { Aborda a importância do papel dos } \\
\text { gestores de recursos humanos que não têm } \\
\text { sido explorado nos textos. }\end{array}$ \\
\hline $\begin{array}{l}\text { Ehring, Tuschen- } \\
\text { Fischer, Jewgenija, } \\
\text { Fischer e Gross } \\
\text { (2010) }\end{array}$ & $\begin{array}{l}\text { - Teoria da Regulação da Emoção } \\
\text { Vulnerabilidade das pessoas à depressão e } \\
\text { estresse relacionados às dificuldades de } \\
\text { regulação da emoção. }\end{array}$ & $\begin{array}{l}\text { Aponta a possibilidade da compreensão de } \\
\text { como desenvolver formas mais eficazes de } \\
\text { regulação da emoção }\end{array}$ \\
\hline $\begin{array}{l}\text { K. J. Harris, } \\
\text { Andrews e Kacmar } \\
(2007)\end{array}$ & $\begin{array}{l}\text { - Teoria da Justiça Organizacional } \\
\text { - Teoria das Trocas Sociais } \\
\text { Verificar relações existentes ou não entre a } \\
\text { Política Organizacional e a Justiça } \\
\text { Distributiva e Processual. }\end{array}$ & $\begin{array}{l}\text { Preenche lacuna existente na literatura } \\
\text { investiga simultaneamente os efeitos da } \\
\text { Política Organizacional, da Justiça } \\
\text { Distributiva e da Justiça Processual } \\
\text { relacionadas à intenção de volume de } \\
\text { negócios e satisfação no trabalho. }\end{array}$ \\
\hline $\begin{array}{l}\text { Hepburn, France e } \\
\text { Francis }(2010)\end{array}$ & $\begin{array}{l}\text { - Teoria da Justiça Organizacional } \\
\text { - Teoria da Justiça Interpessoal } \\
\text { O papel da justiça e estratégias } \\
\text { organizacionais como elementos que } \\
\text { permeiam o retorno ao trabalho }\end{array}$ & $\begin{array}{l}\text { A percepção de trabalhadores acidentados } \\
\text { quanto a conceitos da Justiça Interpessoal e } \\
\text { da Justiça Informacional relacionada ao seu } \\
\text { retorno ao trabalho. }\end{array}$ \\
\hline $\begin{array}{l}\text { Howard e Cordes } \\
\text { (2010) }\end{array}$ & $\begin{array}{l}\text { - Teoria da Justiça Organizacional } \\
\text { - Teoria da Justiça Distributiva } \\
\text { - Teoria da Justiça Processual } \\
\text { - Teoria da Justiça Interacional } \\
\text { - Teoria do Ajuste Pessoa-Ambiente } \\
\text { (Síndrome do Sofrimento Emocional) } \\
\text { Os mecanismos emocionais por meio dos } \\
\text { quais a injustiça é percebida no ambiente } \\
\text { organizacional. }\end{array}$ & $\begin{array}{l}\text { Examina quatro expressões de ausência do } \\
\text { trabalhador resultante da percepção de } \\
\text { injustiça no local de trabalho e exaustão } \\
\text { emocional: absenteismo, intençao de sair } \\
\text { da empresa, trabalho alienado e aumento } \\
\text { do uso de alcool e outras substâncias em } \\
\text { função das injustiças interacionais. }\end{array}$ \\
\hline $\begin{array}{l}\text { Niven, Totterdell e } \\
\text { Holman (2009) }\end{array}$ & $\begin{array}{l}\text { - Teoria da Regulação das Emoções e } \\
\text { Estados de Humor } \\
\text { A regulação das emoções e as formas de } \\
\text { afetar as pessoas. }\end{array}$ & $\begin{array}{l}\text { Apresenta uma classificação sistemática } \\
\text { das estratégias utilizadas pelas pessoas para } \\
\text { afetar os outros de forma intencional. }\end{array}$ \\
\hline $\begin{array}{l}\text { Snyder, } \\
\text { Carmichael, } \\
\text { Blackwell, } \\
\text { Cleveland e } \\
\text { Thornton (2010) }\end{array}$ & $\begin{array}{l}\text { - Teoria da Justiça Organizacional } \\
\text { - Teoria da Justiça Distributiva } \\
\text { - Teoria da Justiça Processual } \\
\text { - Teoria da Justiça Interacional } \\
\text { O estudo examina se os trabalhadores com } \\
\text { deficiência continuam a encontrar mais } \\
\text { experiências negativas de trabalho em termos } \\
\text { de discriminação e injustiça. }\end{array}$ & $\begin{array}{l}\text { Percepção de suporte organizacional e de } \\
\text { supervisão foram apontados como } \\
\text { elementos importantes para reduzir os } \\
\text { efeitos da injustiça no ambiente de trabalho } \\
\text { em relação às pessoas com deficiência } \\
\text { física e com transtornos mentais e } \\
\text { emocionais. }\end{array}$ \\
\hline
\end{tabular}

Nota. Fonte: elaborado pelas autoras. 
Tabela 3

Autores que Abordaram Transtornos Mentais e de Comportamento Utilizando Modelos

\begin{tabular}{|c|c|c|}
\hline Autor(es) & Teorias e Foco abordado & Contribuições \\
\hline Ganster (2008) & $\begin{array}{l}\text { - Modelo Demanda-Controle-Suporte } \\
\text { - Modelo Desequilíbrio Esforço - } \\
\text { Recompensa } \\
\text { - Modelo de Avaliação Cognitiva } \\
\text { - Modelo de Ajuste Pessoa-Ambiente } \\
\text { (P-E fit) } \\
\text { Desafios para medição do estresse e da } \\
\text { tensão no trabalho. }\end{array}$ & $\begin{array}{l}\text { Trata de forma equitativa os } \\
\text { aspectos físicos, emocionais e } \\
\text { relacionais dos sujeitos envolvidos } \\
\text { e do ambiente. }\end{array}$ \\
\hline T. Harris (2007) & $\begin{array}{l}\text { - Modelo Biopsicossocial de Depressão } \\
\text { - Modelo Multifatorial de Depressão } \\
\text { Pesquisa o transtorno depressivo } \\
\text { comparando o processo para casos de } \\
\text { homens e mulheres. }\end{array}$ & $\begin{array}{l}\text { A análise dos dados é feita } \\
\text { tomando por base princípios da } \\
\text { psicanálise. }\end{array}$ \\
\hline \multirow[t]{2}{*}{ Liu e Perrewé (2005) } & $\begin{array}{l}\text { - Modelo Transacional de } \\
\text { Enfrentamento de Estresse (Lazarus) }\end{array}$ & $\begin{array}{l}\text { Apresentam um modelo cognitivo- } \\
\text { emocionais de reações individuais } \\
\text { à mudança organizacional } \\
\text { planejada. }\end{array}$ \\
\hline & $\begin{array}{l}\text { O foco do trabalho diz respeito às } \\
\text { mudanças planejadas (fusões e } \\
\text { aquisições, downsizing, reestruturação } \\
\text { organizacional) e a emoção dos } \\
\text { trabalhadores envolvidos. }\end{array}$ & $\begin{array}{l}\text { Sugere estratégias a serem } \\
\text { adotadas pelos agentes de mudança } \\
\text { para reduzir o impacto nas } \\
\text { emoções dos empregados e as } \\
\text { perdas tanto para as pessoas quanto } \\
\text { para as organizações. }\end{array}$ \\
\hline
\end{tabular}

Nota. Fonte: Elaborado pelas autoras.

A partir do levantamento realizado, optou-se por tomar como referência as seguintes teorias: a Teoria da Avaliação Cognitiva e a Teoria da Justiça Organizacional que contém quatro vertentes, quais sejam: Justiça Organizacional enquanto política geral, Justiça Distributiva, Justiça Procedimental e Justiça Interacional ou Inter-relacional, porque evidenciaram maior relação com a temática da pesquisa.

\section{A teoria da avaliação cognitiva}

A Teoria da Avaliação Cognitiva dá suporte à compreensão do estresse por meio da interdependência das cognições, emoções e comportamentos de avaliação e coping que se referem às inter-relações do sujeito com o meio no qual está inserto.

De acordo com Lazarus e Folkman (1984), na perspectiva da Teoria da Avaliação Cognitiva, os indivíduos fazem inicialmente uma avaliação, se o fato constitui ameaça ou desafio: avaliação primária. Se a avaliação preliminar é que a circunstância constitui uma ameaça de danos ou perdas, passa a haver engajamento do sujeito em uma avaliação secundária: se é ou não apropriado o uso de recursos de enfrentamento disponíveis para lidar com o estresse. As avaliações primárias são influenciadas pelos valores e crenças dos sujeitos a respeito de si próprios e do mundo que os rodeia. O coping, por sua vez, consiste no processo de se lidar com as exigências internas e/ou externas que excedem os recursos para o enfrentamento das exigências do meio. Considera-se então que tanto a avaliação quanto o coping podem ser caracterizados como processos transacionais, uma vez que só ocorrem com o sujeito em relação a algum fato do ambiente no qual está inserto. 
Folkman e Lazarus (1991) afirmam que a emoção facilita e interfere no coping que, por sua vez, é influenciado pela avaliação.

Por decorrência das interferências da emoção, coping e avaliação, de acordo com Edwards, Cable, Williamson, Lambert e Shipp (2006), podem ocorrer desajustes das pessoas em relação ao ambiente em dois momentos. O primeiro se dá quando as exigências do trabalho de uma pessoa não correspondem às suas capacidades para executar o trabalho; o segundo, quando o ambiente não tem a capacidade para suprir seus valores individuais. A construção teórica reforça a opinião de Lazarus (1993), quanto ao conceito de estresse, que continua útil, mas deve ser visto de forma mais abrangente, incluindo emoções positivas e negativas, intrínsecas nas inter-relações de emoção, coping e avaliação e na forma como as pessoas pensam e agem.

No entender de Ganster (2008), a Teoria da Avaliação Cognitiva tem muito apelo: quando se fala de condições psicossociais, há ampla evidência de que a percepção e a interpretação das condições do ambiente são importantes determinantes de ordem afetiva, fisiológica e de reações comportamentais. A importância supramencionada, de modo geral, se deve ao fato de as intervenções gerenciais visarem mais as condições objetivas de trabalho e mostrarem-se impotentes por não alterarem eficazmente as avaliações cognitivas dos participantes. Intervenções objetivas têm sido usadas para mudar os indivíduos no contexto de trabalho (sua autofala, as atribuições e as respostas de enfrentamento) em vez das configurações do próprio trabalho.

\section{A teoria da justiça organizacional}

Howard e Cordes (2010) utilizaram a Teoria do Ajuste Pessoa-Ambiente, para respaldar sua análise em relação aos mecanismos emocionais, em que a injustiça é percebida no ambiente organizacional, de modo geral manifestada sob a forma de fuga do trabalho devido a uma Síndrome de Sofrimento Emocional e Exaustão Emocional. Para os autores mencionados anteriormente há poucas construções teóricas e evidências empíricas para explicar o processo de percepção de justiça no ambiente organizacional, sob a dimensão individual; e pouca atenção tem sido dada à emoção como resultado da injustiça, porque as percepções de justiça ou injustiça despertam respostas emocionais, incluindo um sentido de bem-estar ou uma sensação de sofrimento, respectivamente. Anteriormente Cordes e Dougherty (1993) já haviam registrado que a sensação de injustiça pode manifestar-se de diversas formas, desde a falta de energia até a sensação de que os recursos emocionais se esgotaram, chegando a provocar até o pedido de demissão da empresa, por parte do empregado.

O estudo da Justiça Organizacional teve início tomando-se como base a Teoria da Equidade de Adams, cujo foco foi a percepção de justiça da distribuição de resultados, ou seja, a justiça distributiva (K. J. Harris et al., 2007). Em um segundo momento autores como Folger e Konovsky (1989) voltaram o seu olhar para as percepções de injustiça processual. Posteriormente foi verificado que diferentes formas de justiça servem como fontes de variação das relações de troca. Rupp e Cropanzano (2002) focaram seu interesse na Justiça Interacional ou Interpessoal, na qual o foco é o tratamento justo por parte do supervisor em relação ao empregado. Para os autores a injustiça percebida pode ser uma das mais poderosas fontes de emoções nas organizações. A interação dos valores econômicos, sociais e eventos interpessoais, quando contraditória pode violar os valores pessoais e capacidades dos sujeitos, o que despertaria suas emoções em termos da injustiça. De acordo com Howard e Cordes (2010), emoções como ansiedade, raiva e depressão fazem parte de uma reação afetiva decorrente das divergências percebidas como injustiça organizacional, coerente com o construto da Síndrome de Sofrimento Emocional, proposta por Lazarus (1993). A injustiça percebida não só provoca reações emocionais, como também interfere na realização das atividades dos empregados envolvidos no processo, nas suas relações interpessoais e na sua autoestima (Wenzel, 2000).

Para Cropanzano, Byrne, Bobocel e Rupp (2001), a Justiça Interacional pertence ao lado humano das práticas organizacionais e se relaciona com componentes como honestidade, justiça, respeito e cortesia, entre outros. Por outro lado, segundo Elovainio et al. (2005) e Kausto, Elo, 
Lipponen e Elovainio (2005), profissionais pesquisadores da saúde demonstraram que, em tempos de incerteza, o impacto da Injustiça Interpessoal na saúde é mais forte.

Em resumo, o referencial teórico revelou que os gestores têm papel importante nos casos das relações interpessoais, em que há desequilíbrio de forças e de comportamento, bem como na redução dos impactos de mudanças organizacionais que afetam emocionalmente os trabalhadores. Alguns relatos se mostraram fortes indicadores de estratégias comportamentais de trabalhadores, com o objetivo de afetar aqueles que os cercam. Outras estratégias evidenciam que as pessoas que retornam ao trabalho, após licença psiquiátrica, nem sempre têm que assumir atividades de menor importância.

A seguir apresentam-se o tratamento e a análise dos dados coletados junto aos trabalhadores do Banco.

\section{Uma Síntese dos Autorrelatos dos Participantes da Pesquisa}

Para melhor entendimento, o conteúdo a seguir foi dividido nas categorias encontradas que são: sociodemográficas; estilo de vida; ambiente de trabalho; o tempo de afastamento; relações familiares e sociais durante o quadro; consequências no comportamento pessoal; e relacionamento interpessoal, após o retorno ao trabalho.

\section{Categoria 1: elementos soci-demográficos}

Em termos sociodemográficos foram entrevistados 12 bancárias e 10 bancários. Todos os componentes da amostra são casados e todos têm de um a três filhos, cuja faixa etária é compatível com a idade dos pais (42 a 53 anos). Os participantes da pesquisa possuem de 18 a 29 anos de serviço no Banco.

\section{Categoria 2: estilo de vida}

De acordo com os autorrelatos, durante o quadro do transtorno, os bancários apresentaram um estilo de vida sedentário, uma vez que 21 entrevistados não estavam praticando nenhum tipo de atividade física e declararam não gostar de sair de casa, preferindo vida social menos intensa. Afirmaram que, antes das mudanças implementadas no Banco, seu estilo de vida não era assim; mas com a nova política veio o acometimento da doença, após o que passaram a ter um comportamento diferente, apresentando mau humor ao saírem de casa e ao encontrarem colegas de trabalho. Ficaram claras as dificuldades para a convivência social, para a manutenção de relacionamentos interpessoais fora do círculo familiar, com resistência a tudo o que os colocasse em contato com o mundo, até falar no telefone. Tais sintomas são descritos em OMS (1993), como humor rebaixado e perda de interesse por atividades que normalmente são agradáveis.

Com relação aos hábitos alimentares, verificou-se que, entre todos os participantes, existem 15 que fumam e fazem ingestão de bebida alcoólica em seu cotidiano. Quase metade dos casos teve início com o quadro do transtorno. Segundo a OMS (1993, p. 118) "a mudança de humor pode ser mascarada por aspectos adicionais, tais como irritabilidade, consumo excessivo de álcool". Todos os entrevistados afirmaram que a bebida e o cigarro funcionam como uma espécie de antídoto, diminuindo sua sensação de incapacidade.

Dois dos participantes apresentaram problemas alimentares, havendo perda significativa de peso: um passou de 90 a $60 \mathrm{~kg}$ em seis meses e outro emagreceu cerca de $25 \mathrm{~kg}$ em oito meses. Houve registro de um caso no qual o entrevistado teve problemas de libido.

As características encontradas também fazem parte do quadro dos transtornos, conforme citado por Dalgalarrondo (2008). 
Metade dos entrevistados possuía algum tipo de hobby. Porém, durante o quadro clínico, nove não conseguiram mantê-lo. Jogar bola, pintar, bordar, tocar um instrumento, caminhar, ouvir música e ler foram deixados de lado por tempo prolongado, de quatro a doze meses. A perda de interesse e prazer parecem claros, como relatado: "Fiquei um ano praticamente em cima de uma cama, não queria ler, escrever, nem ouvir música. Eu vivia chorando, minha vida era chorar, chorar e chorar" (E2).

\section{Categoria 3: ambiente de trabalho}

Os participantes da pesquisa relataram vários fatores de risco no seu ambiente de trabalho que interferiram na sua saúde física e mental, tais como: excesso de trabalho, poucos funcionários, pressão das chefias e clientes, horas extras frequentes, ausência de pausas de trabalho, tarefas repetitivas, competição entre os colegas, ambiente estressante, falta de perspectiva de ascensão e falta de reconhecimento pelo trabalho desenvolvido. Para os entrevistados tais fatores foram os motivos que os levaram ao quadro do transtorno e, consequentemente, ao afastamento de suas atividades laborais.

É importante destacar aqui que os autorrelatos feitos pelos entrevistados sugerem que as exigências de aumento de produtividade foram consideradas pelos trabalhadores acima de suas capacidades de desempenho, ou seja, incoerentes com os limites biopsicológicos dos trabalhadores, conforme já constatado por Sardá, Legal e Jablonski (2004).

Ao se observar duas unidades do Banco em um dia típico de funcionamento, foi detectado que o ritmo de trabalho era intenso e acelerado. Uma das possíveis causas citadas pelos pesquisados foi o downsizing, adotado pela empresa como estratégia de uma política de redução de custos, que parece ter agravado a sobrecarga de tarefas e aumentado o ritmo da produção. Segundo 20 entrevistados, atualmente o bancário tem de ser capaz de desenvolver as tarefas que antes eram da responsabilidade de três, às vezes quatro pessoas, "é muito trabalho para poucos funcionários" (E6). Para os respondentes a sobrecarga laboral gera um estado de tensão e estresse no dia a dia da agência, principalmente porque o funcionário tem medo de não conseguir desenvolver bem suas atividades, de não dar conta de seu trabalho, gerando o receio de perder seu lugar.

É importante lembrar que existem discussões referentes à nova configuração do mundo globalizado como a causa de um novo lugar para o ser humano. Segundo Carnoy $(1999$, p. 417) na visão do empregador do mundo neoliberal, o trabalhador ideal é aquele que nunca dorme, não come, nem bebe; não tem filhos e nunca despende tempo em processos de socialização fora do ambiente de trabalho. Trata-se de uma alegação de que os interesses da produção continuam em primeiro lugar, em detrimento do ser humano.

As verbalizações dos entrevistados quanto ao sistema de premiação por produtividade, no qual os bancários se vêm obrigados a atingir as metas e os objetivos propostos pelo Banco sem que haja a oportunidade de discutir tais imposições, refletem a nova postura do empregador no mundo globalizado. Para os participantes da pesquisa isso tem tornado o ambiente organizacional mais competitivo e, às vezes, hostil. Segundo os bancários o mecanismo de estímulo à produtividade implementado gerou muito mais sentimentos negativos do que positivos: no primeiro momento em que uma meta não é atingida, independentemente da razão, há intenso sentimento de frustração, insegurança e medo. Percebe-se aqui, conforme OMS (1993, p. 118), a autoestima e autoconfiança reduzidas e a dificuldade em continuar com o trabalho do dia a dia e as atividades sociais.

Todos os entrevistados consideraram-se bons profissionais, conhecedores do trabalho que executam, mas manifestaram um sentimento de inconformidade e de injustiça, porque compreendem que as metas são ambiciosas e que nem todos conseguirão atingi-las. Ao que parece a venda do serviço bancário vem ganhando importância no momento da prestação dos serviços, requerendo habilidades que antes não eram necessárias. Todo o funcionário passou a ser também um vendedor, mas nem todos têm perfil para isso. E segundo seis dos entrevistados "treinamentos de final de semana" não farão com que as habilidades sejam adquiridas ou desenvolvidas. Cinco dos participantes foram enfáticos ao registrarem que preferem se abarrotar de outras tarefas a "fazer uma venda". 
A nova forma de organização das atividades dos bancários levou a uma constante pressão por parte das chefias e também dos usuários do Banco. Para os entrevistados as cobranças nas reuniões eram exacerbadas e o conceito de times ou equipes de trabalho não funcionava. Na opinião de 16 bancários, existe desproporção entre os esforços que os diferentes profissionais têm que envidar, para que a meta da agência seja atingida. As reuniões passaram a ser, então, locais onde o estado de ânimo e a capacidade das pessoas eram falsamente estimulados. Segundo 13 dos entrevistados, havia muito mais puxões de orelha e acusações de incapacidade do que um reforço positivo de seu desempenho.

No cotidiano já se tornavam comuns os maus tratos e desacatos dos clientes, que queriam receber as prioridades do atendimento veiculadas na mídia. Assim, para seis dos participantes o final do expediente era a um só tempo, um alívio e um receio, porque tinham medo de serem agredidos por clientes fora do Banco e sentiam que, finalmente, mais um dia havia passado. Outra queixa recorrente foi quanto à pausa a que têm direito durante o expediente, ilustrada pela verbalização de E21: "Quando eu ia sair para fazer minha pausa de descanso, tinha cliente que até me xingava porque queria ser atendido logo. Às vezes, ficava até com medo de sair". Pela manhã acordavam antes da hora e ficavam angustiados ao pensarem que teriam que adentrar o mundo do trabalho novamente. Uma das entrevistadas revelou que, durante o processo, tentou suicidar-se, mostrando as cicatrizes nos pulsos. Tais características também estão descritas no OMS (1993).

Por decorrência de todo o processo e de outras razões apontadas os entrevistados disseram que, no final de certo tempo, passaram a sentir ansiedade e agitação; porém com falta de foco nas tarefas, o que os levou à busca de medicamentos e até a automedicação, ingerindo tanto os fármacos sintetizados industrialmente, quanto os fitoterápicos. Há registro de um caso no qual o bancário tem hoje a consciência de que estava tornando-se hipocondríaco (E22).

Todos os entrevistados fizeram uso de medicamentos antidepressivos e/ou ansiolíticos. A verbalização de E11 ilustra a questão: "eu me sentia muito mal e para dormir então só com os remédios". Os trabalhadores afirmaram que, depois de um tempo, tiveram suas angústias e tensões diminuídas, mas que também apresentaram uma neutralidade emocional. Passaram a não se importar com as coisas, tarefas e pessoas e a desenvolver suas atividades de forma lenta, como no relato de E3: "Não tinha vontade de fazer nada, comecei a me afastar de todos. Era um sentimento de tristeza inexplicável. Só quem passa pela doença pode saber!" A partir de certo ponto, foi como se o acompanhamento médico e os medicamentos fossem os advogados de seu comportamento. Não que tivessem perdido o medo da demissão ou de serem destituídos de suas funções, mas que "simplesmente passou a não fazer diferença" (E13). Foi como se perdessem "a noção do perigo" (E8). Os sintomas descritos estão registrados em OMS (1993, p. 118), como "falta de reatividade emocional" e "evidência objetiva de retardo"; e também em Dalgalarrondo (2008), quando trata dos diversos estados de concentração.

Quanto ao clima de cooperação entre os colegas de uma mesma equipe de trabalho, verificou-se que tanto o volume das tarefas quanto as cobranças fizeram com que as amizades e a confiança ficassem arranhadas. Mais de 15 verbalizações foram no sentido de que "às vezes, um quer ser mais que o outro, puxar o tapete do outro; então não existe muita união" (E7).

Em termos da relação chefia-subordinado foram registradas reclamações da falta de perspectiva de ascensão profissional de forma justa. Os entrevistados relataram que se dedicavam muito ao trabalho, mas nunca eram recompensados pela chefia. Tinham vontade de exercer outra função, mas não lhes era dada oportunidade, porque os gerentes beneficiavam a uns e outros não. $O$ sentimento de ter sido traído e não valorizado pela gerência foi constante nas falas dos trabalhadores. Três disseram que haviam passado em concurso interno e que não foram convocados para assumirem como gerentes. Em outros dois casos, foram chamadas pessoas que, segundo as verbalizações, nem tinham sido aprovadas. Foram também recorrentes as argumentações no sentido de que as oportunidades são desiguais e que as pessoas não são consultadas para mudarem de área ou de agência, segundo cinco respondentes. A título de ilustração tem-se: "Eu fui tratada como um lixo pelo meu gerente, fui trocada de agência sem nem me questionarem. Eu fui para a outra agência sem a minha vontade e isso me deixou muito triste e desmotivada" (E13). 


\section{Categoria 4: o afastamento do trabalho}

No geral os entrevistados passaram por um afastamento de seis meses a dois anos, sendo 11 afastados por depressão, seis por estresse, LER/DORT e cinco por depressão, estresse e LER/DORT. Todos os entrevistados manifestaram grande sofrimento com o que chamaram doença, isolando-se da vida. Em todos os casos o tratamento médico foi fator fundamental para a recuperação, considerada lenta. Há quem ainda considere que não se encontra seguro de que o quadro do transtorno vivido se tenha efetivamente extinguido.

\section{Categoria 5: as relações familiares e sociais}

As relações familiares foram muito afetadas durante o período do estresse e da depressão. Enfrentadas as grandes dificuldades, oito funcionários relataram que sabem que seus familiares devem ter-se sentido impotentes e tristes com seu adoecimento. A impotência e a tristeza são entendidas pelos respondentes a partir de situação pessoal, ao revelarem que não saberiam como ajudar alguém passando por situação semelhante. Os bancários sentiram o sofrimento dos familiares; mas, por sua vez, também não conseguiram mover-se na direção de uma ação efetiva, que pudesse mitigar a situação.

Para dois dos entrevistados (E4 e E9), o quadro depressivo que viveram afetou o rendimento escolar dos filhos. Segundo E16, as notas de sua filha diminuíram e ela mesma reduziu suas atividades sociais, preferindo ficar em casa, preocupada com o pai. Em dois casos, os filhos também foram acometidos de transtornos da mesma ordem, como se pode observar pela fala de E20: "Minha filha teve depressão por causa da minha doença e até hoje faz tratamento médico". O que se vê então é a dificuldade em separar emocionalmente os dois ambientes e suas consequências. Foi impossível aos trabalhadores passarem pelo afastamento sem envolverem a família em seus problemas pessoais e de trabalho.

\section{Categoria 6: consequências em relação ao comportamento pessoal}

No final da licença médica, os trabalhadores retornaram ao Banco, mas continuam preocupados com seu desempenho, com o ambiente de trabalho e, sobretudo, com a convivência com as pessoas. Mais da metade dos entrevistados (13) alegou que se tornaram pessoas facilmente irritáveis, sem paciência, que falavam o que pensavam sem medir as consequências. Sua maneira de agir acabava gerando conflitos com os colegas e principalmente com os gerentes. Segundo E17: "Minha colega diz que eu sou uma bomba prestes a explodir". Seis trabalhadores afirmaram que estão conseguindo mudar seu comportamento, que estão organizando melhor seu trabalho e estabelecendo prioridades, conforme relata E22: "Antes, tudo o que alguém me pedia eu não conseguia dizer não, agora é diferente. Primeiro eu questiono qual a prioridade da tarefa; aí depois vejo se vou executar ou não. Hoje consigo dizer que não posso fazer algo, pois estou com muito serviço". Outros três fizeram adaptações e manifestam ainda sentimentos que revelam a relação com o transtorno vivido. Exemplos aparecem nas seguintes verbalizações: "Hoje, faço minha pausa de trabalho, a que tenho direito. Antes achava que eu não podia parar nem para ir ao banheiro" (E1); "Meu ritmo de trabalho, hoje, é mais lento e as pessoas não entendem e nem respeitam. Isso magoa muito a gente" (E14); e "Eu aprendi com minha doença a ser mais devagar. E alguns colegas me chamam de tartaruga" (E18).

Portanto percebem-se claramente as consequências em seu comportamento: quer seja de forma mais equilibrada, quer seja ainda de maneira temerosa, os trabalhadores afastados por transtornos mentais e de comportamento mudaram seu ritmo de trabalho. Já não trabalham tanto quanto antes, vão mais devagar, pois querem mais qualidade de vida e sabem que se trabalharem como antes poderão voltar a ficar doentes. 


\section{Categoria 7: relacionamentos interpessoais após o afastamento}

A mudança de comportamento efetuada pelos bancários que retornaram de licença por transtornos mentais e de comportamento tem gerado problemas de relacionamento interpessoal, pois a nova forma de ser é percebida como não aceita pelos colegas e muito menos pelos gestores. Todos os participantes revelaram sentir-se como objeto de chacota, de risos, de piadas, de cobrança e de escárnio, o que continua afetando suas emoções e reforçando negativamente a sensação de insegurança e falta de confiança. De acordo com os relatos, ao retornarem do afastamento, todos os entrevistados tiveram algum tipo de desentendimento ou ficaram aborrecidos com algum colega de trabalho.

Para os participantes existe discriminação por parte dos colegas, que sempre fazem alguma piadinha a respeito da doença que os acometeu, sendo comum os colegas afirmarem que: "o estressadinho faz corpo mole" (E19), "inventa doença" (E15), "é descuidado e por isso adoece" (E12), "é preguiçoso", parece "porcelana", é neurótico" ou "mentiroso", o que caracteriza a falta de percepção dos diferentes modos de ser e agir e o desrespeito à subjetividade do outro.

Segundo E16, não existe respeito por parte de quem não viveu o transtorno em relação aos limites de atuação de quem enfrentou uma doença psicossomática.

Pelos relatos constata-se que alguns trabalhadores ainda apresentam certas limitações, impostas muitas vezes como consequiência da doença, e que há aqueles que não gostam de trabalhar com quem passou por um transtorno mental ou de comportamento, tornando o aspecto uma fonte de conflito e insatisfação entre as partes: "Eu não voltei $100 \%$ como antes, estou apta para trabalhar, mas tenho limites e alguns colegas não os respeitam e fazem pouco caso disso" (E5); "Um colega me disse uma vez para eu ir para casa, porque eu não tava (sic) produzindo nada mesmo! Eu comecei a discutir com ele, mas depois vi que não valeu a pena. Com o tempo você aprende a não relevar muitas coisas, para não se sentir mais magoada" (E10).

Vários entrevistados relataram que ao retornarem do afastamento foram obrigados a fazer coisas que lhes trouxeram descontentamento. Entre elas deviam permanecer separados dos normais. Assim, em alguns casos foi criado um setor específico, local para o qual foram transferidos os "reabilitados", que é uma expressão comum no ambiente pesquisado. "O problema é que o empregado não volta com uma função definida, o que gera um sentimento de muita ansiedade e insegurança" (E2), pois "A gente não sabe o que vai fazer e tem a sensação de que o nosso trabalho não é mais tão importante como era antes" (E7).

Alguns têm sentimento de inutilidade ou até incapacidade, pois os próprios colegas os veem assim. As atitudes discriminatórias para com os que regressam causaram sofrimento, manifestado por lágrimas e medo, o que dificulta a estabilização de quem passa ou passou por transtorno mental e de comportamento, aqui caracterizados mais como o estresse e a depressão. A verbalização de E6 ilustra os argumentos: "Eu me sentia um inútil e fui muito discriminado ao retornar ao trabalho, pois me colocaram para atender telefone, fazer serviço de estagiário e até trocar o papel do banheiro me pediram para eu (sic) fazer". Tais comportamentos podem acarretar um clima de insatisfação, de falta de cooperação, de conflitos e desmotivação no funcionário, com consequências funestas não só em meio da equipe, como também daquelas que fazem parte do ambiente familiar e social.

O relacionamento fora do horário de trabalho também ficou prejudicado porque para evitar as piadinhas e até mesmo para não falar mais a respeito da doença, o que deixa o funcionário que passou pelo quadro muito irritado, todos os entrevistados disseram que não participam mais das festas da equipe nem saem juntos para momentos de happy hour.

Quando perguntados quanto ao sentimento que existe hoje em relação ao trabalho, os 22 participantes foram unânimes em afirmar que se sentem desmotivados, desvalorizados e de alguma forma acham que as metas continuam inatingíveis; que não há como todos os funcionários terem altos desempenhos, como os estabelecidos em função da grande disputa do mercado. 


\section{Uma Breve Discussão dos Achados da Pesquisa}

Vive-se num paradigma no qual as empresas esperam contar com super-heróis e não com seres humanos passíveis de falhas e erros e deixam de levar em consideração que as pessoas são diferentes no seu modo de ser. Toda a individualidade e os processos de subjetivação parecem estar relegados, esquecendo-se ou desprezando-se o fato de que o corpo humano é um sistema complexo e delicado suscetível ao desgaste e à morte.

Os dados coletados junto a trabalhadores do Banco puderam ser sintetizados, conforme se descreve a seguir, lembrando tratar-se da percepção dos pesquisados.

Em termos sociodemográficos, pode-se dizer que houve um equilíbrio quanto ao gênero e uma certa homogeneidade em relação ao estado civil (todos casados) e com filhos em idade proporcional à própria faixa etária na qual estão os participantes da pesquisa.

Como era de esperar em quadros de estresse e depressão, os afastamentos se caracterizaram pelos sentimentos que configuram a doença e também por quadros de DORT/LER.

Pode-se dizer que o estilo de vida dos entrevistados durante o transtorno foi sedentário e, de certa forma, antissocial, pois deixaram de conviver com os amigos e até de frequentar ambientes religiosos. Nota-se que o acometimento da doença mudou o comportamento daqueles que foram afastados, incluindo também a mudança de humor e a qualidade dos relacionamentos. Tais aspectos ficaram claros, quando os participantes evidenciaram o abandono de seus hobbies e da prática de alguma atividade física.

É importante registrar também que houve mudança nos hábitos alimentares, incluindo aspectos considerados nocivos à saúde, como a ingestão de bebida alcoólica e o uso do fumo. Em alguns casos, as consequências foram drásticas, tais como a perda excessiva de peso e uma tentativa de suicídio. Houve também registro de perda da libido.

Os principais fatores que conduziram aos transtornos vividos pelos entrevistados foram: excesso de trabalho, pressão das chefias e clientes, horas extras frequentes, ausência de pausas de trabalho, tarefas repetitivas, competição entre os colegas, ambiente estressante, falta de perspectiva de ascensão e falta de reconhecimento no trabalho desenvolvido. Os fatores relatados provocaram o despertar de sentimentos, cujas consequências se fizeram em sua vida, seu comportamento e suas relações, resultando no afastamento de suas atividades laborais por incapacitação temporária.

$\mathrm{O}$ ambiente laboral pareceu configurar-se dentro da tipicidade do trabalho de um Banco, com destaque para o que vem ocorrendo no mercado, em termos da competitividade exigida. $\mathrm{O}$ tratamento dispensado pelos gestores também não se mostrou diferente de outras organizações que reforçam os altos desempenhos e o atingimento de metas e, de certa forma, punem os empregados que não conseguem chegar aos patamares esperados. No entanto, os participantes da pesquisa revelaram que não possuem capacidade para lidar com as diferenças entre as pessoas, considerando todos dentro de um padrão que não fora estipulado, quando iniciaram suas carreiras.

$\mathrm{O}$ ritmo acelerado e as exigências do mercado parecem ter restringido alguns direitos dos funcionários e aumentado a tensão no ambiente de trabalho. Tais aspectos são evidenciados pelo aumento do número de reclamações e de ações contra os prestadores de serviços, o que parece ter levado a instituição a aumentar a pressão no ambiente organizacional.

Existem pessoas que conseguem trabalhar sob pressão e outras não. As características pessoais dos que têm menor capacidade de lidar com a pressão os levam a ter dificuldade para manter seu comportamento e seus sentimentos estáveis por um tempo; mas a mudança é inevitável. De início recorrem aos medicamentos e, podem, como nos casos estudados, ser obrigados ao afastamento por incapacidade temporária. 
As consequências na vida, nos hábitos alimentares, nas práticas cotidianas e relações interpessoais daqueles que se veem acometidos pelo estresse e pela depressão, são grandes. Há quem afirme que jamais serão os mesmos. Que nunca se recuperarão por completo.

No final da licença, retornaram ao serviço; mas continuam preocupados com seu desempenho, com o ambiente de trabalho e, sobretudo, com a convivência com as pessoas. Ainda não se sentem plenos no gozo de sua capacidade laboral, em virtude das alterações em seus sentimentos, emoções e nas novas relações estabelecidas no Banco. $\mathrm{O}$ fato de fazerem valer seus direitos os coloca como pessoas ainda não aptas ao trabalho, sem resistência, fracas, sujeitas a brincadeiras de mau gosto por parte dos colegas. Isso continua afetando seu emocional, gerando insegurança e desconfiança naqueles que retornam ao labor.

É importante destacar também que a organização parece não estar preparada para receber os profissionais afastados no momento do seu retorno, pois não existe um programa de reintegração ao trabalho. Nenhum dos 22 entrevistados recebeu orientações em relação às suas novas atividades, quando foi encerrado o período de afastamento.

Tudo isso gera um clima de insatisfação, descontentamento, conflito e desmotivação. Os resultados sugerem que as relações tidas com os antigos colegas, antes do transtorno sofrido, não são passíveis de recuperação. No entanto é importante registrar que não houve uma iniciativa dos gestores de recursos humanos em tal direção.

Constatou-se que a família sofre muito durante todo o processo da doença, podendo as consequências ser estendidas aos seus integrantes. Observou-se ainda que para a recuperação e preparação do retorno ao exercício laboral, ela exerce papel fundamental, ao dar apoio e força para que o afastado volte mais confiante para o trabalho.

Os achados da pesquisa mostram que as novas tecnologias levaram os bancos a uma reestruturação que parece estar ligada aos transtornos estudados. Isso porque, quando os atuais funcionários foram selecionados, os cargos e funções tinham uma natureza. Com o advento da tecnologia foi possível ao cliente fazer seu autoatendimento, o que provocou reestruturações nas funções das inúmeras pessoas que atendiam nos caixas. O número de gerentes de contas aumentou, fato que foi justificado pelo discurso do atendimento personalizado ao cliente. Mas com isso também vieram novas funções, para as quais o perfil dos bancários poderia não ser adequado, como, por exemplo, as vendas, das quais reclamaram, resultando, em alguns casos, em desempenhos abaixo do que se espera do profissional. Além disso, o baixo desempenho pode ser a causa da tensão que iniciou o processo do transtorno vivenciado.

No final, pode-se dizer que os sentimentos relatados pelos participantes variaram entre: raiva, incapacidade de reação, indiferença, culpa, medo, injustiça, incompreensão; enfim, intolerância a respeito da diversidade de modos de ser e viver.

\section{Considerações Finais}

Com encerramento desta pesquisa, pode-se dizer que seu objetivo foi atingido, qual seja: identificar e descrever, na percepção de alguns trabalhadores de um Banco Público Estadual, quais as consequências em sua vida laboral e pessoal, ao retornarem ao trabalho após um período de licença médica, devido a transtornos mentais e de comportamento.

Em relação ao caso estudado, pode-se dizer que para um mesmo fator estressor existem diferentes formas de percepção e significado devido às interpretações que os indivíduos fazem de suas condições de trabalho e de seus relacionamentos, o que é relevante para as questões de ordem afetiva, fisiológica e as reações comportamentais dos participantes da pesquisa. 
Os bancários pesquisados revelaram alguns comportamentos de coping em duas dimensões: no ambiente de trabalho em relação às tarefas e às pessoas e no ambiente social, junto aos familiares e amigos. Não se pode dizer que o enfrentamento surtiu o efeito desejado; mas houve um movimento do sujeito na direção oposta aos fatos percebidos, uma vez que os valores que, antes do afastamento, eram desconsiderados passaram a ocupar um lugar importante no processo de análise do ambiente e das interações interpessoais. Antes do afastamento os movimentos de coping eram frágeis, resultando em violentação dos valores dos sujeitos. Após o retorno ao trabalho alguns bancários, até então afastados, passaram a defender seus pontos de vista, suas prioridades, incluindo a própria saúde e bem-estar. Observar os horários de trabalho, negar-se a fazer horas extras, negar-se a seguir um ritmo de trabalho exaustivo, são outros exemplos de coping relatados pelos entrevistados.

De forma inconsciente, a Teoria da Avaliação Cognitiva se fez presente, pois houve uma análise do que lhes fazia bem e do que lhes trazia prejuízo, mesmo sem conhecerem as possibilidades de intervirem no processo. Um fato revelador no caso de quem não fez o movimento, foi o abandono das práticas de exercícios e hobbies, mostrando que, conforme Folkman e Lazarus (1991), a emoção interfere no coping.

Os desajustes que antes se davam em relação à capacidade dos pesquisados dentro das exigências do trabalho assumiram uma dimensão menor, por duas razões: a primeira porque ao retornarem passaram a desempenhar outras funções e a segunda porque alteraram o ritmo do desempenho das tarefas (produtividade), tornando-o mais condizente com seu estado físico e emocional. Tal comportamento parece encontrar respaldo na tentativa dos trabalhadores de reduzirem a carga de estresse, a fim de evitarem uma recaída em termos dos transtornos vividos.

Há evidências que sugerem que, após o retorno ao trabalho, a injustiça foi percebida tanto em nível organizacional (excesso de trabalho antes do afastamento), quanto relacional. Ao que parece, houve injustiça por parte dos supervisores em relação ao empregado, ao aceitarem a determinação dos gestores de recursos humanos quanto às novas atribuições e locais de trabalho dos trabalhadores que estavam retornando à organização. Além disso, o sofrimento que os entrevistados passaram a enfrentar diz respeito às diferenças de valores entre os bancários que foram afastados e os que permaneceram em seus postos de trabalho, manifestadas pelas expressões pejorativas utilizadas para adjetivar a forma como os colegas que gozaram da licença médica desempenhavam suas tarefas. Há evidências de que tais comportamentos tenham afetado a própria autoestima e as formas dos relacionamentos familiares dos profissionais que foram afastados, devido a algum tipo de transtorno. $\mathrm{O}$ resultado é condizente com a Síndrome do Sofrimento Emocional, mas não foi detectado em outros estudos. No mínimo pode-se dizer que os que ficaram apresentam maior resistência às pressões e frustrações do ambiente de trabalho, quando comparados aos que entraram em adoecimento.

Quanto ao papel e intervenção dos gestores de recursos humanos, observou-se que não foram levadas em consideração algumas recomendações feitas por pesquisas realizadas no ambiente organizacional. Primeiro, porque mudaram as pessoas de lugar, colocando-as para desempenhar tarefas de menor importância ou sem uma tarefa determinada. Segundo, porque não houve um acolhimento por parte dos gestores no sentido de reintegrar o trabalhador à sua função original.

No caso do Banco pesquisado, fica claro que não tem sido dada atenção às emoções e aos transtornos mentais e de comportamento decorrentes da injustiça organizacional e, muito menos, àquela decorrente dos relacionamentos interpessoais. Acredita-se que uma escuta dos sujeitos por parte dos gestores de recursos humanos, ou até mesmo de seus superiores, possa sugerir modos de intervenção que venham a minimizar os danos emocionais causados aos trabalhadores que retornam às atividades laborais em processos de restauro e significação de sua vida profissional. Por consequiência, amparando o trabalhador enquanto ser humano, é possível que surjam melhorias no ambiente organizacional e para a empresa como um todo.

Assim, acredita-se que esta pesquisa possa trazer contribuições para o setor de Recursos Humanos do Banco, pois seus resultados poderão despertar a atenção dos gestores, pelo menos, para 
repensar a forma de reintroduzir no ambiente laboral os trabalhadores que foram afastados, devido a transtornos mentais e de comportamento.

Finalmente sugere-se a realização de novas pesquisas, incluindo a percepção dos gestores de recursos humanos a respeito do retorno dos trabalhadores afastados por transtornos mentais e de comportamento e as possibilidades de intervenção no ambiente, de forma a acolher profissionais em recuperação emocional.

Outra sugestão seria aplicar o Teste de Rosenzweig, em um estudo comparativo, a fim de se verificar a existência ou não de diferenças nos modos de lidar com a pressão e com a frustração. Seria necessário incluir como sujeitos da pesquisa, tanto os trabalhadores que foram afastados quanto os que permaneceram em serviço. Tal pesquisa poderia ser complementada com outra, na qual se buscaria compreender o perfil dos trabalhadores que não adoeceram e como lidaram com as mudanças ocorridas em seu local de trabalho em comparação com os que foram acometidos por transtornos mentais e de comportamento.

Artigo recebido em 12.08.2010. Aprovado em 19.09.2011.

\section{Referências}

Alexanderson, K., \& Norlund, A. (2004). Aim, background, key concepts, regulations, and current statistics. Scandinavian Journal of Public Health, 32(63), 12-30. doi: 10.1080/14034950410021808

Ayres, K. V., Brito, S. M. O. de, \& Torquato, A. R. S. de (2002, setembro). Tecno-Stress em bancários: fontes, sintomas e estratégias defensivas. Anais do Encontro Nacional da Associação Nacional de Pós-Graduação e Pesquisa em Administração, Salvador, BA, Brasil, 26.

Ballone, G. J. (2002). Estresse no trabalho. Recuperado em 30 setembro, 2009, de http://www.psiqweb.med.br/site/?area=NO/LerNoticia\&idNoticia=67

Carnoy, M. (1999). The family, flexible work and social cohesion at risk. International Labor Review, 138(4), 411-429. doi: 10.1111/j.1564-913X.1999.tb00395.x

Chamon, E. M. Q. O. de, Marinho, R. C. de, \& Oliveira, A., L (2006, setembro). Estresse ocupacional, estratégias de enfrentamento e síndrome de Burnout: um estudo com a equipe de enfermagem de um hospital privado do Estado de São Paulo. Anais do Encontro Nacional da Associação Nacional de Pós-Graduação e Pesquisa em Administração, Brasília, DF, Brasil, 30.

Cooper, C. L. (2007). A natureza mutante do trabalho: o novo contrato psicológico e os estressores associados. In A. M. Rossi, P. L. Perrewé, \& S. L. Sauter (Orgs.), Qualidade de vida no trabalho: perspectivas atuais da saúde ocupacional (pp. 3-8). São Paulo: Atlas.

Cordes, C. L., \& Dougherty, T. W. (1993). A review and integration of research on job Burnout. Academy of Management Review, 18(4), 621-656.

Cropanzano, R., Byrne, Z. S., Bobocel, D. R., \& Rupp, D. E. (2001). Moral virtues, fairness heuristics, social entities, and other denizens of organizational justice. Journal of Vocational Behavior, 58(2), 164-209. doi: 10.1006/jvbe.2001.1791

Dalgalarrondo, P. (2008). Psicopatologia e semiologia dos transtornos mentais. Porto Alegre: Artmed.

D'Cruz, P., \& Noronha, E. (2010). The exit coping response to workplace bullying: the contribution of inclusivist and exclusivist HRM strategies. Employee Relations, 32(2), 102-120. doi: $10.1108 / 01425451011010078$ 
Edwards, J. R., Cable, D. M., Williamson, I. O., Lambert, L. S., \& Shipp, A. J. (2006). The phenomenology of fit: linking the person and environment to the subjective experience of personenvironment fit. Journal of Applied Psychology, 91(4), 802-827. doi: 10.1037/00219010.91.4.802

Ehring, T., Tuschen-Fischer, B., Jewgenija, S., Fischer, S., \& Gross, J. J. (2010). Emotion regulation and vulnerability to depression: spontaneous versus instructed use of emotion suppression and reappraisal. Emotion, 10(4), 563-572. doi: 10.1037/a0019010

Elovainio, M., Bos, K. van den, Linna, A., Kivimaki, M., Ala-Mursula, L., Pentti, J., \& Vahtera, J. (2005). Combined effects of uncertainty and organizational justice on employee health: testing the uncertainty management model of fairness judgments among finnish public sector employees. Social Science \& Medicine, 61(12), 2501-2512. doi: 10.1016/j.socscimed.2005.04.046

Folger, R., \& Konovsky, M. A. (1989). Effects of procedural and distributive justice on reactions to pay raise decisions. Academy of Management Journal, 32(1), 115-130.

Folkman, S., \& Lazarus, R. (1991). Coping and emotion. In A. Monat \& R. S. Lazarus (Eds.), Stress and coping, an antology (pp. 207-227). New York: Columbia University Press.

Foster, D., Corso, J. M. D., Rógio, K. D. de, Gomes, L., Virtuoso, L. A., \& Silva, W. V. (2007, outubro). Estresse ocupacional: mudanças impostas na área de tecnologia em fase de implantação do sap R/3. Anais do Encontro de Administração da Informação da Associação Nacional de Pós-Graduação e Pesquisa em Administração, Florianópolis, SC, Brasil, 1.

Ganster, D. C. (2008). Measurement challenges for studying work-related stressors and trains. Human Resource Management Review, 18(4), 259-270. doi: 10.1016/j.hrmr.2008.07.011

Grisci, C. L. I., \& Bessi, V. G. (2004). Modos de trabalhar e de ser na reestruturação bancária. Sociologias, (12), 160-200. doi: 10.1590/S1517-45222004000200007

Halbesleben, J. R. B., \& Zellars, K. L. (2007). Stresse e a interface trabalho família. In A. M. Rossi, P. L. Perrewé, \& S. L. Sauter (Orgs.), Qualidade de vida no trabalho: perspectivas atuais da saúde ocupacional (pp. 56-72). São Paulo: Atlas.

Harris, K. J., Andrews, M. C., \& Kacmar, M. (2007). The moderating effects of justice on the relationship between organizational politics and workplace attitudes. Journal of Business and Psychology, 22(2), 135-144. doi: 10.1007/s10869-007-9054-9

Harris, T. (2007). Vulnerable to depression. British Journal of Psychotherapy, 23(4), 547-562. doi: 10.1111/j.1752-0118.2007.00050.x

Hepburn, C. G., France, R. L., \& Francis, L. (2010). Successful return to work: the role of fairness and workplace-based strategies. International Journal of Workplace Health Management, 3(1), 724. doi: $10.1108 / 17538351011031902$

Howard, L., \& Cordes, C. L. (2010). Flight from unfairness: effects of perceived injustice on emotional exhaustion and employee withdrawal. Journal of Business and Psychology, 25(3), 409-428. doi: 10.1007/s10869-010-9158-5

Kausto, J., Elo, A.-L., Lipponen, J., \& Elovainio, M. (2005). Moderating effects of job insecurity in the relationships between procedural justice and employee wellbeing: gender difference. European Journal of Work and Organizational Psychology, 14(4), 431-452. doi: $10.1080 / 13594320500349813$

Koopmans, P. C., Bültmann, U., Roelen, C. A. M., Hoedeman, R., Klink, J. J. L. van der, \& Groothoff, J. W. (2011). Recurrence of sickness absence due to common mental disorders. 
International Archives of Occupational and Environmental Health, 84(2), 193-201. doi: 10.1007/s00420-010-0540-4

Laplanche, J., \& Pontalis, J. B. (2004). Vocabulário da psicanálise. São Paulo: Martins Fontes.

Lazarus, R. S. (1993). Why we should think of stress as a sugset of emotion. In L. Goldberg \& S. Bredmitz (Eds.), Handbook of stress, theoritical and clinical aspects (pp. 21-39). New York: Free Press.

Lazarus, R. S., \& Folkman, S. (1984). Stress, appraisal, and coping. New York: Springer.

Lipp, M. N. (Org.). (1996). Pesquisa sobre estresse no Brasil: saúde, ocupação e grupo de risco. São Paulo: Papirus.

Liu, Y., \& Perrewé, P. L. (2005). Another look at the role of emotion in the organizational change: a process model. Human Resource Management Review, 15(4), 263-280. doi: 10.1016/j.hrmr.2005.12.001

Martin, D., Quirino, J., \& Mari, J. (2007). Depressão entre mulheres da periferia de São Paulo. Revista de Saúde Pública, 41(4), 591-597. doi: 10.1590/S0034-89102007000400013

Moreira, D. A. (2004). O método fenomenológico na pesquisa. São Paulo: Pioneira Thomson Learning.

Murta, S. G., \& Tróccoli, B. T. (2004). Avaliação de intervenção em estresse ocupacional. Psicologia: Teoria e Pesquisa, 20(1), 39-47. doi: 10.1590/S0102-37722004000100006

Nakayama, M. K. (1997). A influência da cultura organizacional na predisposição do gerente ao estresse ocupacional (Tese de doutorado). Universidade Federal do Rio Grande do Sul, Porto Alegre, RS, Brasil.

Nielsen, M. B. D., Madsen, I. E. H., Itmann, U. B., Christiensen, U., Diderichsen, F., \& Rugulies, R. (2010). Predictors of return to work in employees sick-listed with mental health problems: findings from a longitudinal study. European Journal of Public Health Advance Acess published,1, 1-6. doi: 10.1093/eurpub/ckq171

Niven, K., Totterdell, P., \& Holman, D. (2009). A classification of controlled interpersonal affect regulation strategies. Emotion, 9(4), 498-509. doi: 10.1037/a0015962

Oliveira, F. A., Kilimnik, Z. M., \& Silva, G. A. V. (2005, setembro). Avaliação dos fatores de pressão no trabalho médico e sua relação com o estresse: um estudo de em uma unidade ultra-sonografia da rede pública em comparação com unidades da rede privada. Anais do Encontro Nacional da Associação Nacional de Pós-Graduação e Pesquisa em Administração, Brasília, DF, Brasil, 29.

Olivier, M., \& Behr, R. R. (2006). Relações interpessoais: Espaços contínuos ou fronteiras delimitadas entre trabalho e família? In Garcia, A. (Org.), Relacionamento interpessoal - estudos brasileiros (pp. 22-48) Vitória: Ufes.

Organização Mundial da Saúde. (1993). Classificação de transtornos mentais da CID-10. Porto Alegre: Artmed.

Paiva, K. C. M. de, \& Couto, J. H. S. do (2007, junho). Qualidade de vida e estresse gerencial pós 'choque de gestão': o caso da COPASA-MG. Anais do Encontro Gestão de Pessoas e Relações de Trabalho da Associação Nacional de Pós-Graduação e Pesquisa em Administração, Natal, RN, Brasil, 1. 
Pluta, D. J., \& Accordino, M. P. (2006). Predictors of return to work for people with psychiatric disabilities: a private sector perspective. Rehabilitation Counseling Bulletin, 49(2), 102-110. doi: 10.1177/00343552060490020101

Rossi, A. M. (2007). Estressores ocupacionais e diferenças de gênero. In A. M. Rossi, P. L. Perrewé, \& S. L. Sauter (Orgs.), Stress e Qualidade de vida no trabalho: perspectivas atuais da saúde ocupacional (pp. 9-18). São Paulo: Atlas.

Rupp, D. E., \& Cropanzano, R. (2002). The mediating effects of social exchange relationships in predicting workplace outcomes from multifoci organizational justice. Organizational Behavior and Human Decision Processes, 89(1), 925-946. doi: 10.1016/S0749-5978(02)00036-5

Sardá, J. J., Legal, J. E., \& Jablonski, J. S. (2004) Estresse: conceitos, métodos, medidas e possibilidades de intervenções. São Paulo: Casa do Psicólogo.

Snyder, L. A., Carmichael, J. S., Blackwell, L. V., Cleveland, J. N., \& Thornton, G. C. (2010). Perceptions of discrimination and justice among employees with disabilities. Employ Respons Rights J, 22(1), 5-19. doi 10.1007/s10672-009-9107-5

Tanure, B., Carvalho, A. N., \& Andrade, J. O. (2007, setembro) Fontes de tensão no olimpo empresarial brasileiro: tempo de menos, mudanças e sobrecarga demais, muito orgulho e o peso do teatro corporativo. Anais do Encontro Nacional da Associação Nacional de Pós-Graduação e Pesquisa em Administração, Rio de Janeiro, RJ, Brasil, 31.

Tolfo, S. R., Philippi, D. A., Grandi, C. A., Piccinin, D., \& Noernberg, T. R. (2005, setembro). O processo de reestruturação produtiva de uma empresa de telecomunicações: o caso dos trabalhadores remanescentes, demitidos e que aderiram ao PDI. Anais do Encontro Nacional da Associação Nacional de Pós-Graduação e Pesquisa em Administração, Brasília, DF, Brasil, 30.

Vaez, M., Rylander, G., Nygren, A., Asberg, M., \& Alexanderson, K. (2007). Sickness absence and disability pension in a cohort of employees initially on long-term sick leave due to psychiatric disorders in Sweden. Social Psychiatry and Psychiatric Epidemiology, 42(5), 381-388. doi: 10.1007/s00127-007-0189-9

Vicente, L. B. (2005). Psicanálise e psicossomática - Uma revisão. Revista Portuguesa de Psicossomática, 7(1-2), 257-267.

Wenzel, M. (2000). Justice and identity: the significance of inclusion for perceptions of entitlement and the justice motive. Personality and Social Psychology Bulletin, 26(2), 157-176. doi: $10.1177 / 0146167200264004$

Zampier, M. A., \& Stefano, S. R. (2004). Estresse nas empresas de grande porte da região de Guarapuava. Revista de Administração Nobel, 1(3), 11-20. 